\title{
DIOS Y LA LÓGICA DEL ABSURDO. UNA VISIÓN SOBRE LA NATURALEZA HUMANA Y SU CONDICIÓN EN LA FILOSOFÍA DE ALBERT CAMUS
}

\section{GOD AND THE LOGIC OF THE ABSURD. AN INSIGHT ON THE HUMAN NATURE AND ITS CONDITION IN THE PHILOSOPHY OF ALBERT CAMUS}

\author{
Andrés Abel Iglesias Marrero' \\ 1 - Universidad de La Habana, La Habana, Cuba \\ 1. Email: andrewchurches321@gmail.com ORCID: https://orcid.org/0000-0003-3083-5327
}

Recibido: 01/11/2021 Aceptado: 11/01/2022

\begin{abstract}
Cómo Citar: Iglesias Marrero, A. A. (2022). Dios y la lógica del absurdo. Una visión sobre la naturaleza humana y su condición en la filosofía de Albert Camus. Dialektika: Revista De Investigación Filosófica y Teoría Social, 4(9), 19-27. https://doi.org/10.51528/ dk.vol4.id72
\end{abstract}

\begin{abstract}
Resumen:
Los albores del pensamiento camusiano proyectan la existencia de una impresión equiparable a la experiencia estética en el ser humano, que es dada a conocer como el absurdo. A grandes rasgos consiste en un estado de contradicción propiciado por el divorcio -o la desproporción que existe-, entre el hombre y el mundo que le rodea, expresado en la relación entre las intenciones de aquel y la mudez de la realidad que le circunda. Pero además de su entorno, uno de los más grandes misterios para el hombre es precisamente el de su propia naturaleza. Resulta atrevido el intento de una definición, sin embargo, la obra de Albert Camus propone una visión que vincula la propia existencia del hombre a una de sus facultades esenciales: la razón. Por ello, la contribución del presente artículo es entrelazar la noción camusiana del absurdo con la de naturaleza del hombre y la condición humana, sin pasar por alto la de Dios y su relevancia para un análisis original y diferenciado. La importancia de desarrollar este tema radica en que el pensamiento contemporáneo no es ajeno a las cuestiones sobre el hombre, su naturaleza y su condición, y rescatar el valor que atesora la filosofía de Albert Camus es indispensable en una línea de pensamiento que hasta el día de hoy permanece inconclusa.
\end{abstract}

Palabras clave: absurdismo, existencialismo, ontología, metafísica.

\begin{abstract}
:
The dawn of Camussian thought projected the existence of an impression comparable to the aesthetic experience in the human being, which is made known as the absurd. Broadly speaking, it consists of a state of contradiction caused by divorce - or the disproportion that exists - between man and the world that surrounds him, expressed in the relationship between his intentions and the muteness of the reality that surrounds him. But in addition to his environment, one of the greatest mysteries for man is precisely that of his own nature. The attempt at a definition is daring, however, the work of Albert Camus proposes a vision that links the very existence of man to one of his essential faculties: reason. For this purpose, the contribution of this article is to intertwine the Camussian notion of the absurd with that of nature of man and the human condition, without overlooking that of God and its relevance for an original and differentiated analysis. The importance of developing this theme lies in the fact that contemporary thought is not alien to questions about man, his nature and his condition, and rescuing the value that Albert Camus's philosophy holds is essential in a line of thought that to this day remains unfinished.
\end{abstract}

Keywords: absurdism, existentialism, ontology, metaphysics. 


\section{DIOS Y LA LÓGICA DEL ABSURDO. UNA VISIÓN SOBRE LA NATURALEZA HUMANA Y SU CONDICIÓN EN LA FILOSOFÍA DE ALBERT CAMUS}

«Contrariamente a muchos ilustres contemporáneos, yo no creo que el hombre sea, por naturaleza, un animal social. A fuer de sincero, pienso lo contrario. Pero sí creo, lo que es muy diferente, que no puede vivir ya fuera de una sociedad cuyas leyes son necesarias para su supervivencia física» (Camus, 1985, p. 346).

El absurdo, como concepto medular en la obra de Albert Camus, es la consecuencia lógica de un mundo privado - o al menos divorciado- de sentido y de Dios. En el ser humano, la asimilación del absurdo precisa de la reafirmación de la idea de extrañez frente a un mundo que no es claro ni se explica ante sus interrogaciones. Para elaborar esa sentencia, Camus precisó una visión acerca del hombre, de la naturaleza y de la condición humana, que se distinguió en algunos aspectos de las de sus contemporáneos. Una visión en la que la naturaleza humana, por ejemplo, se consideró el motivo -o el fin último- de la moral si se toma como la parte más irreductible y única que llena de orgullo al ser y lo descubre superior en oposición a los otros seres vivos -y las cosas- que le rodean. Se dice superior porque el ser humano es el único que carga con el peso de una razón que le impide, bajo determinadas circunstancias históricas, contentarse con el orden de cosas existente. Gracias a ella, todos los hombres participan de una misma naturaleza, que se complementa de un trasfondo moral y se identifica con una forma de trascendencia de la que todos somos participes. Sin embargo, aludir a la naturaleza humana precisa necesariamente de un análisis sobre el antecedente de esa realidad, es decir, sobre la condición humana.

Porque una condición es aquello sin lo cual algo no puede existir; decir naturaleza humana sin condición (o incondicionada) significará algo imposible, incluso decirlo a la inversa puede considerarse un esfuerzo incompleto o vacío. En la filosofía europea contemporánea se utiliza la expresión «condición humana» para designar el contenido de la «naturaleza humana», y Albert Camus comparte dicha acepción. Este «contenido» no es otro que la visión del hombre en su situación existencial desde una perspectiva trágica, y de este modo Camus modifica el concepto de «condición humana» ${ }^{1}$ desplazando su significación de antecedente hacia aquello que lo caracteriza, o lo que le hace propiamente hombre. Dicho de otro modo, la condición humana está en su propia naturaleza, la cual incita a una incesante búsqueda de verdades.

Así, la condición humana tendrá una doble acepción ya que, si remite a la razón y al cuerpo en cuanto concierne a la naturaleza del hombre, entonces se corresponderá una metafísica y una histórica en cuanto refiera a su condición.

La primera, condición metafísica ${ }^{2}$, define al hombre en un estado de exilio, que en la filosofía de Camus significa la actitud de distanciamiento del hombre hacia un mundo del cual no se siente

1. Considérese a pensadores como Friedrich Nietzsche, Jean Paul Sartre o Soren Kierkegaard.

2. Entiéndase como sinónimo de condición absurda, que posteriormente Camus llamará condición cruel y limitada, condición sin porvenir, vana condición, pero todas vienen a ser lo mismo. 
parte y donde nada tiene un sentido claro $\mathrm{y}$ explícito. Dicha condición se caracteriza por la absurdidad, el pesimismo y la injusticia de una vida divorciada de universales abstractos. Para Camus esta condición es el objeto de la rebelión metafísica ya que, frente a la absurdidad, se encuentra una grandeza implacable e inmanente en el hombre llamada dignidad que exige en primer lugar sentido y unidad, y en segundo lugar no ser tratado como un medio sino como un fin en la disposición divina del orden de las cosas.

La condición metafísica se manifiesta así en la idea de que el hombre es un ser contradictorio, y en su contradicción rechaza al mundo tal y como es, pero se niega a abandonarlo. Solo frente a situaciones extremas algunos considerarán la posibilidad de suicidio, porque por muy pésima o agobiante que sea la vida, en líneas generales el ser humano se aferra a ella y una inmensa mayoría no desea dejarla. Esto, en líneas generales, es la esencia del absurdismo camusiano y aporta -para su reflexión- los tres puntos siguientes: 1) El hombre lleva el sello fatídico de un condenado a muerte porque ese destino es inevitable, 2) es un extraño entre sus semejantes porque encuentra hostilidad y rechazo en los otros, y 3) es visto como un exiliado en su universo -frente al mundo, la naturaleza y Dios.

La principal contradicción que aviva el absurdo es la incesable necesidad humana de perdurar en un mundo mortal y limitado que lo aprisiona, donde, por ley universal todo lo que es está destinado eventualmente a no ser. El auténtico reconocimiento del absurdo consiste en la simple inquietud que aparece cuando el hombre se sitúa con relación al tiempo, y reconoce su pertenencia insignificante; consiste en el horror que se apodera de él cuando advierte que el mañana que anhelaba es su peor enemigo.

En lugar de rechazar el porvenir, se desvive por poseerlo en su totalidad, pero esta tarea es imposible. Así, en la lógica camusiana del absurdo, la muerte es uno de los primeros descubrimientos: es abrumador el hecho mismo de que vivir es estar condenado a morir porque, para Camus, la muerte no tiene nada de sagrado ni de venerable, en cambio no hace otra cosa que suscitar el miedo y el malestar en el ser. La conciencia de la muerte -o de vivir para morir- es la evocación a una inquietud constante, a una angustia latente en la que volver a la nada se contrapone a una existencia en el absurdo. En su desesperación el hombre opta por reconstruir un espacio familiar y tranquilo que propicie cierta paz interior, pero, objetivamente, la exigencia natural de su espíritu para burlar el porvenir permanecerá siempre insatisfecha. Sólo podrá aferrarse a instantes inmediatos $y$ fulgurantes de plenitud, y esa es la realidad del ser humano que hace uso de razón; la condición metafísica es absurda. "Deseamos que el amor dure, y sabemos que no dura; aunque por milagro durase toda una vida, seguiría siendo incompleto» (Camus, 1985, p. 283).

Como segundo punto de reflexión se distingue que la absurdidad de la condición metafísica implica un divorcio entre los hombres mismos, en la relación con sus semejantes. Si bien el hecho de que todos los seres humanos (y los seres vivos en sentido general) comparten el mismo destino -la muerte- como si fuesen participes de una gran comuna solidaria, en reiteradas ocasiones el hombre no se manifiesta solidario con sus similares. Más que un aliado encuentra en el otro un enemigo, un extraño, y ello lo atestigua la 
historia. En ese sentido compete, como antecedente de la naturaleza humana, un segundo aspecto de su condición, y es histórico.

El hombre, ser social en virtud de su supervivencia en el mundo hostil que le rodea, fundamenta esa supervivencia en torno a un «contrato social» que establece límites y pautas a ciertas libertades individuales, con el objetivo de salvaguardar su integridad y posesiones no solo del entorno sino también del hombre mismo. Pero, como afirmaba Hobbes, dicho contrato o pacto entre los hombres es el primer paso para la fundación de un monstruo de magnitudes bíblicas, un Leviatán que como superestructura estatal alienará el poder, y en su forma capitalista también al propio hombre convirtiéndolo en mercancía.

¿Cómo considerar al hombre un ser social por naturaleza, cuando manifiesta una tendencia creciente hacia la privatización? ¿Por qué privatiza la propiedad sobre los bienes, las ideas (con patentes), los recursos naturales (el agua, el combustible, etc.), e incluso al propio hombre cuando «contrata» a otro? ¿No iría esa tendencia contra su propia naturaleza social? La respuesta es no, porque en realidad su naturaleza no es la de un ser social.

En sociedad -en el mejor de los casos- el hombre aprende a compartir, a ser solidario, a ayudar al prójimo, y en esencia aquellos valores que conforman un ideal altruista. Pero esto no es constitutivo de todos los grupos humanos ni de todas las circunstancias de su vida social, porque también puede desarrollar su egoísmo, su ambición o su codicia. El modo de producción capitalista y la privatización de la propiedad reduce la fuerza de trabajo del hombre a una mercancía que puede ser comercializada en el mercado laboral, y la vida en sociedad, específicamente en dichas sociedades, hace al hombre esclavo de su producto, y en cierto grado también se hace esclavo (o esclavizador) de los otros hombres.

La vida en sociedad significa un conflicto que oprime y aliena al trabajador contra el trabajador, en una competencia por salarios más elevados o beneficios laborales o compensaciones. Esto en última instancia anula por completo el sentido último de sus vidas y su existencia, y los reduce a seres autómatas de aspiraciones banales. He aquí la reafirmación de que el hombre es un extranjero, separado o alienado de sí mismo -de su naturaleza- y de sus semejantes mientras exista una estructura social y relaciones de producción regidas por el capital. Cuando se marca la distinción del «yo» con el «otro», lo privado pasa a ser exclusivo del «yo» y ajeno a ese «otro», y la civilización significará en su esencia un exilio, porque no hay manera de definir en esta gran comunidad al «otro» más que como un ser extraño y perverso.

El peso filosófico que Camus brinda a estas cuestiones, sobrepasa las condiciones materiales que critica el marxismo, y apunta hacia un aspecto oculto del ser en el que el hombre también será un extraño consigo mismo. En su identidad personal, el «yo» no puede definirse completamente, porque siempre hay algo desconocido e irreductible que escapa a cualquier delimitación. La vida en sociedad obliga al ser humano a moldearse dos caras: una que personifica en sus relaciones con los demás, y otra que es la auténtica y propia que oculta y nunca se permite mostrar en público. Mediante la primera, el hombre establece vínculos con aquellos «otros» seres a partir de las afinidades y semejanzas de sus personas, pero, si mostraran la 
cara encerrada en la profundidad de cada ser, de inmediato se eliminarán esos lazos afectivos que los familiarizan y aquellas personas conocidas se convertirán en seres extraños. Por tanto, la condición histórica del hombre es aquello que hace al ser humano a través de sí mismo, o, dicho de otro modo, aquello que le define a partir de sus acciones y su obrar en el tiempo.

En el tercer y último punto reflexivo se encuentra paradójicamente el comienzo del absurdo, es decir, el exilio metafísico del hombre en el mundo y en Dios. Este, al que refiere Camus con su lógica del absurdo, es dado por el divorcio del hombre y el universo en que habita porque el último no proporciona respuesta alguna a sus inquietudes metafísicas. Tal es un divorcio ontológico -que se asocia con el punto anterior (el exilio social)- ya que en ese estado de abandono del ser se manifiesta su condición histórica que implica la soledad de una vida en sociedad.

En el lenguaje ordinario se utilizan las palabras «extranjero» y «exiliado» para designar las circunstancias de alguien que esta fuera de su país de origen, pero existe una sutil e importante distinción entre ellas. Un extranjero en sentido estricto es alguien que no es natural de las tierras en que reside; un exiliado es alguien que ha sido condenado por otro - $u$ otros- a vivir fuera de su tierra natal, como consecuencia de haber cometido un gran fallo -o un grave error-. La filosofía de Albert Camus concibe al hombre según su naturaleza y condición- como ambas, un extranjero y un exiliado al mismo tiempo; separado del ser, como si estuviera separados de su país de origen ${ }^{3}$.

Así, el abandono y la soledad son temas recurrentes en las obras literarias de Albert Camus, y aunque no lo afirme de forma explícita, en ellas se considera que el autor del mencionado exilio del hombre es Dios. Según Marcel Mélançon (1976), «en la obra La peste se puede notar un vocabulario religioso subyacente que refiere a la condición de los exiliados como una especie de castigo colectivo o una maldición divina» (p. 78) ${ }^{4}$. De hecho, la alusión camusiana a la rebelión metafísica se funda en la atribución a Dios de la injusticia de vivir en un mundo donde prospera el mal y la muerte. Esto provoca al ser humano la angustia existencial de un mundo abandonado a su suerte, y el tormento de habitar en una sociedad inhumana. Sin embargo, aunque la angustia no es un concepto central en el pensamiento de Camus a diferencia de Kierkegaard, o lo que se traduce como la náusea para Sartre-, si lo es la soledad.

El estado del hombre en el universo silencioso $y$ absurdo en que se encuentra ${ }^{5}$ es para Camus tan radical que le arrastra a la conclusión de la inexistencia -o al menos la ineficacia- de un poder superior. Al vincular la naturaleza del hombre al absurdo hace que el descubrimiento de este último le predisponga a vivir sin Dios, por ser este la causa de todo, incluidos los males. Para desarrollar esa idea Camus utiliza la noción de injusticia de la condición humana, o en su forma más explícita,

3. Camus considera al hombre como un extranjero porque habita en un mundo que no le pertenece, y que tampoco responde a las exigencias de su naturaleza racional. A la vez lo considera exiliado de una patria perdida y privado de recuerdos de los tiempos pasados, si es que tuvo alguna experiencia de vida anterior.

4. Traducción del autor: Le vocabulaire religieux de La Peste, de L'Etat de Siège, de tous les exilés, parle de «punition collective», de «malédiction divine» (Melançon, 2017, p. 78).

5. Para ser más específicos el silencio irracional del mundo y el no menos irracional de Dios. 
los derechos del hombre a la «unidad» $\mathrm{y}$ «claridad» epistémica que se atropellan en su tránsito por el mundo. En el viaje mundano, todos los seres vivos deben morir, el mal va a contrarrestar al bien, la tristeza remplazará a menudo la felicidad, y tal disposición debe de precisar un artífice, y este alude Camus- es exclusivamente Dios. Si desde la teología se entiende que el mal es necesario en la creación divina, entonces esta creación es desde luego inaceptable e injusta; la vida es más cruel que el propio hombre, y su sufrimiento no tiene razón de ser.

Para Camus Dios es incapaz de hacer el bien y, sin embargo, el ser humano que es capaz de hacer tanto el bien como el mal a voluntad, ha convertido su historia, la historia de la humanidad, en un voluntarioso espectáculo circense. Nietzsche procuró la muerte de Dios, pero no lo hizo con la de los hombres. Más que una negación divina, la propuesta nietzscheana es la afirmación absoluta del «amor fati», y el problema del divorcio entre el hombre y el mundo se soluciona reconciliándose o resignándose- con la fatalidad del mal. Sin embargo, en el pensamiento de Camus es inconcebible tal reconciliación ya que, muerto Dios, aún quedan los hombres -o la historia- que debe de comprenderse y edificarse, y requerirá una más difícil reconciliación.

Si este mundo no tiene un sentido superior que lo corrija, si el hombre no tiene por destino más que al hombre mismo, entonces la fatalidad no es el sinsentido del mundo -como propone la filosofía de Nietzsche y el nihilismo-, sino la imposibilidad para el despliegue del hombre. Y lo único que puede impedírselo es la muerte. En el universo de la rebelión camusiana, la muerte exalta la injusticia divina porque reafirma el mundo tal cual es. Aquí se encuentra una de las razones por las que Camus critica el suicidio y persigue la vida, a pesar de considerar su condición absurda. Por eso Sísifo consternado con el castigo que le someten los dioses, no se suicida, sino que se convierte en el héroe del absurdo. Sin estima a los dioses y odiando la muerte, se apasiona por la vida, aunque esta sea el tormento de empujar una roca hacia la cima de una colina para luego verla rodar colina abajo, y empezar de nuevo en un bucle infinito. Por esa actitud frente el absurdo de su condición, uno debe imaginarse a Sísifo feliz.

¿Acaso existe algo más inútil que el trabajo de Sísifo? ¿Hay algo más inútil que el suplicio del ser dispuesto en función de no lograr nada? La situación camusiana en que se encuentra Sísifo, su condena, es precisamente una alegoría de la vida y la existencia del hombre. Todo el trabajo realizado va a ser en vano frente al trágico final que nos espera. Hay en todos los hombres un deseo de permanencia frente a ese destino final, y por ello generalmente se busca refugio en la religión o en un propósito que alimente la esperanza. Sin embargo, el hombre camusiano no hace nada por lo eterno, puesto que la nostalgia de una vida ulterior le resulta indiferente. Para el hombre absurdo separado de Dios no queda otra solución más que aferrarse al tiempo y a lo efímero; su nostalgia debe canalizarse a través del mundo y en su entorno.

Esto guarda estrecha relación con la verdad y el conocimiento. ¿Puede tener algún valor la verdad si va a estar condicionada -entre otras cosas- por la temporalidad? ¿Puede el hombre aprehender de alguna manera al mundo, su realidad, o incluso a Dios? Para comprender el mundo, para determinar verdades, el hombre necesita entender la lógica de 
su objeto de estudio desde lo humano, y marcarlo con su sello. Esto corresponde a un clásico problema epistemológico en el cual: para comprender la realidad no existe otra vía que reducirla a los términos que el pensamiento -la razón humana- considere comprensibles, y una vez hecho esto y se logre encontrar cierta armonía lógica esta no será más que una simple reducción fenoménica. «Entre la certidumbre que tengo de mi existencia y el contenido que trato de dar a esta seguridad hay un foso que nunca será colmado. Seré siempre extraño a mí mismo» (Camus, 2014, p. 21).

Dicho de otro modo, el universo de un gato no es el universo de un simio. La quintaescencia de aquello que llama Dios -o el universo divino-, es ontológicamente incomprensible desde el universo del hombre. Y lo mismo sucede con el mundo. Ahí está su límite y a la vez su desgracia, en el desnivel constante entre lo que se imagina saber y lo que sabe realmente. ¿De quién y de qué el hombre puede decir con toda seguridad «lo conozco»? ¿En qué disposición puede afirmar lo mismo respecto a lo que él llama Dios?

Esto no es más que un vuelco sobre la duda cartesiana a la que Camus da un giro ontológico. No se trata de postular el mundo como consecuencia externa del "yo», ni tampoco negarlo como harían los escépticos, más bien se trata de afirmar su desconocimiento. No hay nada que le asegure al hombre que el mundo que experimenta es enteramente suyo, más que su propia experiencia. Las leyes, las descripciones, los predicamentos, se convierten en agua que se desliza entre los dedos ante lo irracional, la nostalgia humana y lo absurdo que surge de su enfrentamiento con el mundo. Así, para el espíritu absurdo de Camus la realidad es simplemente irrazonable y termina -abrupta y necesariamentecon toda lógica que pueda aplicarse a su existencia. No hay nada más que «eso» y el espíritu absurdo del hombre es quien pone sus límites. Esto, lejos de calmar su angustia la cataliza y la potencia, porque la razón es un instrumento de pensamiento y no el pensamiento mismo.

De este modo, lo que tradicionalmente se asume por «verdad», en el universo camusiano, se suprime. El mundo es incomprensible e irracional, y el deseo de claridad y de unidad -o pertenenciadel hombre se hace inútil, puesto que la razón no lo satisface ni podrá hacerlo jamás. La «verdad» no está en la correspondencia entre la «idea» que se tiene de algo y la «cosa»-o ese algo concreto-, sino en la no correspondencia permanente en la relación hombre-mundo. Lo absurdo es entonces, el lazo que une al hombre con el mundo, y esto es lo único discernible claramente, esto es lo único verdadero para Camus. La nostalgia de unidad del primero, el universo disperso y silencioso del segundo, y la contradicción que los encadena y los une, conforman la amalgama camusiana de la verdad. Si se da por cierto esto, habrá necesariamente que reajustar la conducta del hombre y seguirla en todas sus consecuencias como fundamento existencial. Aparece un sentido ante el absurdo y el hombre se convierte en la medida de todos sus actos, por tanto, el hombre es su vida -o lo que hace en vida-, y nada más.

«Yo decía que el mundo es absurdo y me adelantaba demasiado. Todo lo que se puede decir es que este mundo, en sí mismo, no es razonable. Pero lo que resulta absurdo es la confrontación de ese irracional y ese deseo desenfrenado de claridad cuyo llamamiento resuena en lo más profundo del hombre» (Camus, 2014, pp. 22-23). 
Para Camus este divorcio -entre el espíritu que desea y el mundo que decepciona- es el catalizador de la rebelión. No se debe suprimir esa nostalgia del hombre, ni tampoco intentar conciliar el universo irracional con la razón, como hace la escuela existencialista. Para Camus se trata de vivir y de pensar con esos desgarramientos sin disfrazar las evidencias ni suprimir a lo absurdo. Aquellos que lo intentan, suponen para el espíritu absurdo un retroceso frente a lo que el propio espíritu les pone de manifiesto. Este es un principio de razón, pero por si solo no es suficiente.

Sobre esta idea Camus es bien explícito: O el mundo tiene un sentido superior que sobrepasa todas sus contradicciones, o lo único verdadero son esas contradicciones. En otras palabras: O existe Dios como solución teológica a las contradicciones mundanas, o existe el tiempo como solución fatal a un mundo absurdo. Vale destacar que la negación de la posibilidad de un sentido trascendente no significa la ausencia -o falta- de un sentido externo al hombre, sino todo lo contrario, significa que, al afrontar el enigma del mundo, el hombre encuentra un sentido que descifra mal porque le deslumbra, es decir, que sobrepasa los límites de la razón. Este es el «silencio irrazonable del mundo» al que refiere Camus en El mito de Sísifo; ese universo silencioso e indescifrable escapa a toda trascendencia porque es inmanente a las cosas mismas.

Según la lógica camusiana, la vida será mejor vivida si se purgara del sentido superior divino que se le intenta otorgar, ya que la carencia de sentido absoluto no significa la supresión de las formas particulares de la existencia. Al quitarle el sentido a la vida se queda la vida misma, pura en su esencia, y de la misma manera que la vida de un autor puede cobrar sentido a partir de sus obras, en un mundo absurdo es posible vivir si todo se restringe a lo humano y a lo contingente. Si el hombre conoce a partir de su condición, y de su condición deriva su naturaleza, entonces para comprender al mundo necesita reducirlo a un principio racional y razonable que caiga dentro de sus propios límites. Y si se asume esa postura, entonces ¿Qué verdades puede el hombre reconocer sin hacer que intervenga una esperanza externa, que no significa nada dentro de los límites de su propia naturaleza y condición? La reconciliación -o la ansiada unidad- aparece solo en el momento de la muerte, cuando todo acaba y ya nada más se puede hacer, mientras tanto solo es posible el absurdo. No puede haber absurdidad fuera de la razón humana ni del mundo, porque lo absurdo termina como todas las cosas, con la muerte. 


\section{REFERENCIAS}

Camus, A (1996). Obras 3. Alianza Editorial, Madrid.

Kierkegaard, S. (1844). El concepto de la angustia. Tr. Demetrio G. Rivero. Recuperado de https://ebiblioteca.org/lecturas/?/v/14498

Melançon, M. (1976). Albert Camus. Analyse de sa pensée. Edición Digital realizada el 19 de febrero del 2007, de la colección "Les classiques des sciences sociales". Recuperado de http://classiques.uqac.ca/contemporains/ melancon_marcel_j/albert_camus_1976/ Albert_Camus_1976.pdf

Sartre, J. (1938). La Náusea. 9ª Edición. Editorial Época, D.F. 